\title{
A rare case of post traumatic isolated bilateral abducens nerve palsy
}

\author{
Manish Jaiswal $^{1}$, Saurabh Jain ${ }^{1}$, Ashok Gandhi ${ }^{1}$, Achal Sharma ${ }^{2}$, \\ R.S. Mittal ${ }^{1}$ \\ ${ }^{1}$ Department of Neurosurgery, SMS medical college and hospital \\ ${ }^{2} J L N$ Marg, Jaipur (302004), Rajasthan, India
}

\begin{abstract}
Although unilateral abducens nerve palsy has been reported to be as high as $1 \%$ to $2.7 \%$ of traumatic brain injury, bilateral abducens nerve palsy following injury is extremely rare. In this report, we present the case of a patient who developed isolated bilateral abducens nerve palsy following minor head injury. He had a Glasgow Coma Score (GCS) of 15 points. Computed tomography (CT) images \& Magnetic Resonance Imaging (MRI) brain demonstrated no intracranial lesion. Herein, we discuss the possible mechanisms of bilateral abducens nerve palsy and its management.
\end{abstract}

Key words: abducens nerve palsy, sixth nerve palsy, false localizing sign.

\section{Introduction}

The Abducens nerve is the most vulnerable nerves due to its extremely long extracerebral intracranial course. It usually presents as false localizing sign in various intracranial disorders like brain tumour \& idiopathic intracranial hypertension. It is usually unilateral \& associated with major head injury with brain stem injury and associated neurological findings due to compression near petrous apex and narrowed bony canal (Dorello's canal). Isoleted bilateral involvement of Abducens nerve is uncommon in head injury \& extremely rare in minor head injury. Here we are discussing an unusual case of minor head injury where the patient presented with bilateral sixth nerve palsy without any other neurological deficit \& all investigations failed to find cause.

\section{Case Report}

A 40 year old male was admitted with the history double vision after an episode of minor head injury (Glasgow Coma Scale 15/15). The injury was sustained due to head on collision of his bike with a moving car coming from opposite direction on a local road at very low speed. Immediately following the accident, the patient had transient loss of consciousness but regained consciousness after about five minutes. As seen by nearby relative there is no history of vomiting, seizure or bleeding from ear nose or mouth. Patient was brought to our 
hospital where he was given primary care. On examination bilateral lateral rectus palsy was present (Figure 1). No other positive finding recorded in general physical, neurological and ophthalmological examination.

Computed Tomography Head (CT Head) (Figure 2) and Magnatic Resonance Imaging (MRI) of Brain (Figure 3) were failed to reveal any significant finding explaining this condition.

A formal diagnosis of post traumatic isolated bilateral Abducens palsy was made. Patient was managed conservatively with oral steroids (Prednisolone $1 \mathrm{mg} / \mathrm{Kg}$ per day dose) for ten days followed by alternate day regime for next three weeks and tapering regimen along with oral methylcobalamine. The Abducens palsy improved with time and resolved partially in six months.

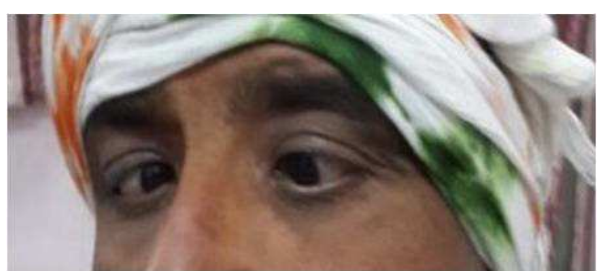

Figure 1 - Isolated bilateral Lateral rectus (Abducens Nerves) palsy in minor head injury patient

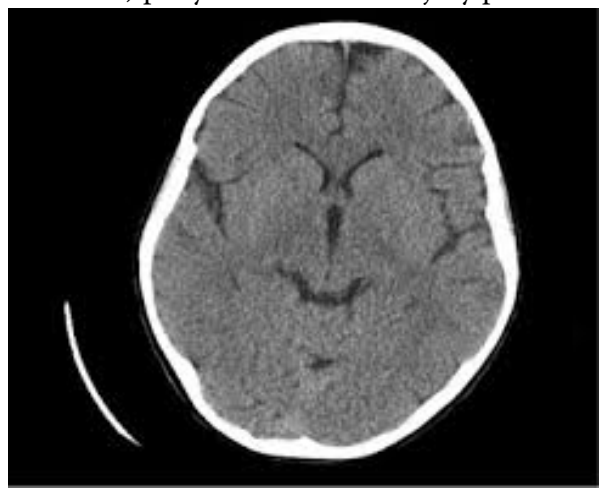

Figure 2 - Computed Tomographic Scan Head Showing no intracranial lesion or fracture

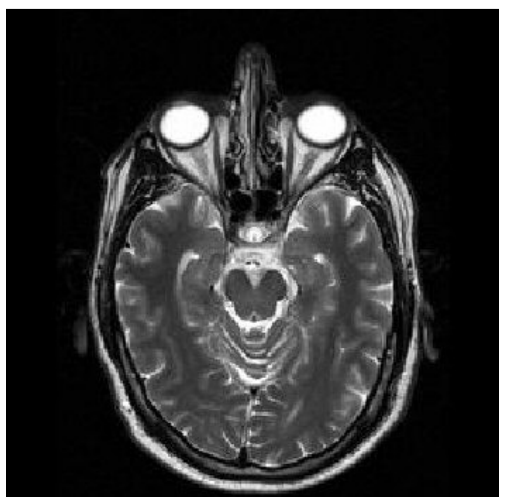

Figure 3 - Magnatic Resonance Imaging Brain Showing no patology justifying to abducens nerve palsy

\section{Discussion}

Abducens nerve originates from the brain stem and course up to the lateral rectus muscle. Initially this nerve runs up to petrous ridge and changes direction approximately $120^{\circ}$ forward. The further path of this delicate nerve is traversed in a very narrow bony tunnel known as Dorello's canal. After passing through Dorello's canal, the nerve passes through the cavernous sinus and the superior orbital fissure and innervates the lateral rectus muscle $(1,2,3,5)$.

Two possibilities are theorized for damage of abducens nerve. One is an angle near the petrous apex and another is passage through the bony canal (Dorello's canal).

Bilateral abducens nerve palsy following trivial trauma is a relatively rare occurrence. Berlit et al evaluated 165 patients suffering from abducens nerve palsy as the main presenting symptom (6). A vascular origin (29.7\%), inflammatory diseases (19.4\%) and tumours $(10.9 \%)$ were the most common causes while traumatic abducens paresis (3.1\%) was rare out of which only $10 \%$ of the 
DOI: 10.2478/romneu-2014-0068

patients were presented with bilateral palsy. Posttraumatic bilateral abducens palsy has been reported mainly in various case reports thus emphasising its relative rarity.

Holmes et al in his study concluded that non-recovery from acute traumatic sixth nerve palsy was associated with complete palsy and/or a bilateral palsy (7). Treatment of posttraumatic bilateral abducens nerve palsy is usually conservative though Kao et al showed that such patients treated with subtenon injection of botulinum toxin showed higher recovery rates than patients treated conservatively (8). Mutyala et al reported a spontaneous improvement rate of $27 \%$ in unilateral traumatic sixth-nerve palsy and $12 \%$ in bilateral traumatic sixth-nerve palsy (9). However, Holmes et al reported an overall spontaneous recovery rate of $73 \%$ (7). Spontaneous recovery was more frequent in unilateral cases $(84 \%)$ than in bilateral cases (38\%) (7). Our patient was managed conservatively with oral steroids and showed partial improvement after six months follow up.

\section{Conclusion}

In conclusion bilateral isolated sixth nerve palsy is an extremely rare occurrence in minor head injury and very few cases have been reported in available literature. This case highlights the occurrence and management of posttraumatic bilateral sixth nerve palsy. Full or partial recovery is the natural history in the majority of traumatic abducens nerve palsies, and this is an important consideration when counselling patients with such injuries.

\section{Correspondence}

Manish Jaiswal

A 33/48 A 2, Omkareshwar, Varanasi, 221001,

Uttar Pradesh, INDIA

Phone - 091-8933816028,

E-mail-manishmlnmc@gmail.com

\section{References}

1. Arias MJ. Bilateral traumatic abducens nerve palsy without skull fracture and with cervical spine fracture: case report and review of the literature. Neurosurgery. 1985;16:232-234.

2. Marconi F, Parenti G, Dobran M. Bilateral traumatic abducens nerve palsy: case report. J Neurosurg Sci. 1994;38:177-180.

3. Limnaios EE, Papageorgiou CT. Bilateral abducens nerve palsy. Ophthalmologica. 1980;181:326-329.

4. Uzan M, Hanci M, Sarioglu AC, et al. Bilateral traumatic abducens nerve paralysis with cervical spine flexion injury. Eur Spine J. 1996;5:275-277.

5. Baker RS, Epstein AD. Ocular motor abnormalities from head trauma. Surv Ophthalmol. 1991;35:245-267.

6. Berlit P, Reinhardt-Eckstein J, Krause KH. Isolated abducens paralysis-a retrospective study of 165 patients. [Article in German] Fortschr Neurol Psychiatr 1989;57:32-40.

7. Holmes JM, Beck RW, Kip KE, Droste PJ, Leske DA. Predictors of non recovery in acute traumatic sixth nerve palsy and paresis. Ophthalmology 2001;108:1457-60.

8. Kao LY, Chao AN. Subtenon injection of botulinum toxin for treatment of traumatic sixth nerve palsy. J Pediatr Ophthalmol Strabismus 2003;40:27-30.

9. Mutyala S, Holmes JM, Hodge DO, Younge BR. Spontaneous recovery rate in traumatic sixth-nerve palsy. Am J Ophthalmol 1996;122:898-9. 